\title{
EdTech'88 - Designing for Learning
}

\author{
Garth Boomer \\ Associate Director-General of Education (Curriculum) \\ Education Department of South Australia
}

\begin{abstract}
Garth Boomer was asked to be the Conference Moderator for EdTech'88 the Australian Society for Educational Technology's biennial Conference held in Canberra in September 1988 [http://ascilite.org.au/asetarchives/confs/edtech88/edtech88_contents.html]. By design, his role was not clearly defined by the organisers - he was merely required to start the Conference off by providing delegates with some focus for the following three days of sessions, and to come back at the end of the Conference with his interpretation of what had happened. Here is what he said in both opening and closing the Conference.
\end{abstract}

\section{Part One - Opening Address}

In making an introductory speech to this Conference, I must say that I feel some empathy with Alice in Wonderland or Dorothy about to meet the Tin Man.

As a rank lay person in the field of educational technology, I scan my conference program with feelings of awe and apprehension. Forbidding language leaps from the pages and knocks fruitlessly on the doors of my innocent mind - "optical disc formats"; "CD-ROM"; "ISDN"; "HyperCard"; "interactive videos for lateral thinking"; "learning delivery systems"; and "CBT Authoring Packages". I ponder the possibilities of "serialisation" or the eliciting of "personal constructs" and prepare to enter new realms of thinking about distance education, remote teaching and technology-led, industry-based training. Wide-eyed, I anticipate following this yellowbrick road in a quest to understand the latest educational wizardry of $\mathrm{Oz}$.

But then I am comforted to know that this is a conference about designing for learning. Learning is my game. I love it and love thinking about how people do it. And as for designing, you might say that I am now, after 
almost thirty years in the business of education, a believer that design, in its fullest sense, is at the heart of human cognition. Indeed the very concept of design neatly encapsulates for me a personal learning theory. I therefore carry the word and its meaning with me everywhere as a compact, portable scanner of education. Classrooms without learners with designs are classrooms where you will observe mindless training as opposed to education, which requires presence of mind.

To design is to recognise and shape a problem to the point where it is "set" and then to imagine what it would be like if the problem were solved. This imagining of a better state of things (or a better tool or machine or product) provides the impetus, the fuel, the tension which will drive the learning that accompanies problem solving. In other words, at the heart of all worthwhile learning is personal intention fueled by imagination. This leads to a state which I shall call "having designs" and what more traditional learning theorists might describe as "entertaining hypotheses". There follows research, information gathering, observation etc. (using any of the various media available to human searchers), a kind of "casing" of the possibilities, trial and error and then testing and evaluation. In other words "design" embodies a classical theory of deliberate, as opposed to incidental, learning.

If you accept my view that deliberate learning is synonymous with designing, then this conference may well have been entitled "Designing for designing in industry and education".

So I am comforted. I tell myself that, technical, specialist language aside, this is to be a conference where we are going to learn more about how to make learning better through the use of better tools and better machines. In order to do this we must keep firmly in mind how it is that people learn; how it is that the human mind goes about making sense of the world. If we lose sight of that, then we are in danger of being mesmerised and enraptured with our tools and machines as clever ends in themselves. We will become reprehensible indulgers in technology for its own sake.

In addition to keeping our eyes on learners, we will need also to keep imagining the practical contexts in which teachers and industry trainers operate. Technology developed under relatively ideal test conditions may prove cumbersome, unworkable and uneconomical in real world contexts.

As a layperson in an auditorium of specialists, I understand that my role at this conference is to play the part of a receptive but judiciously sceptical teacher. My job is to say: "Convince me that you can contribute to improving my performance as a curriculum designer and teacher. Make things easier for me and my students." If you cannot get me to imagine how I and my students will be better off through using the tools you have designed, then I shall not use them. 
On the other hand, if you are brilliant at exploiting the "gee-whiz" syndrome, you may be able so to dazzle me with the tool-as-plaything that I will rush back to my school as some kind of convert and begin practising in a state of technological hypnosis. This has been known to happen before. Banks of unused machines, once state-of-the-art frontrunners for some technological cult, exist in many schools and industries, attesting to what happens when the magic of conversion wears off. I shall try not to be "magicked" at the Conference. In my role as teacher, I shall be a hardheaded pragmatist. I am overloaded, stressed, sometimes bewildered by the growing complexities of my job. Ease my burdens.

I suppose that I should declare my definition of technology. Technology describes a human endeavour which has to do with making things work or getting things done more effectively and efficiently. It is the art and science of reducing human effort or amplifying human effort whether that effort be mental or physical. In the realm of learning, technology can free the human mind from lower levels of computation and analysis so that it can operate on higher order problems; it can open up wider access to information; it can make available simulations and re-creations of real-life events and operations; it can provide retrievable outside-the-brain storage of data; it can bridge distance and it can, in various "cloning" ways, emulate teachers.

"The computer, for instance, is an extension, an amplifier of aspects of the mind and as such is an instrument for bringing into greater effect the potential of personkind. It is an analog of aspects of the human brain but it has no mind. ...Aspects of mind can be mapped onto computers. Thus computers allow us, within limits, to look inside our own and other people's heads. Furthermore, they allow us to stand on the shoulders of other people's intelligence. They increase our scope, our vision and our field of influence."

(From "Zen and The Art of Computing", in Garth Boomer (1985). Fair

Dinkum Teaching and Learning. Montclair: Boynton/Cook)

There is another aspect of technologies as media that is central to learning. Jerome Bruner has said that each time we use a different medium to explore content or territory we intensify our knowledge of that territory. For instance if I write about "conference", I pay attention to certain features of "conference". If I dramatize "conference" I see it from a changed perspective. If I film "conference" the "lens" changes my understanding again. I might also paint, graph, relay by DUCT, or even do a multimedia coverage of "conference". Each new medium will transform and intensify my understanding of that which I am exploring.

All this amounts to the conclusion that the greater the variety of media used by a teacher, the more the students will learn about a particular topic or text. 
Designers of technology try to make the presently impracticable practicable. By making-believe, they eventually make things happen. They think the unthinkable and once it has been thought, we, the users, often remark on how simple, elegant and even self-evident, in retrospect, the invention is. We have a remarkable, almost nonchalant capacity these days, to take the miraculous for granted.

Because technology is the practice of giving people an edge, an advantage, that is, greater power (and I don't mean to refer to anabolic steroids), we cannot and must not ignore the politics of technology Looking at your program at least superficially, I wonder to what extent people will be addressing questions of social justice and equity and considering what long-term societal consequences there will be if there is differential access to the advantages of technology. I suspect that much of the exciting technology which will be discussed at this conference, like fire, will be capable both of great good and great evil. Perhaps a better way of putting it is that technique is applied by people and therefore whatever is invented will serve human purposes. Human purposes in turn can serve evil or inequitable ends. To misquote Shakespeare:

"There is nothing either good or bad but using makes it so."

We need, therefore, to be eternally vigilant to see that the advantages inherent in the technical are equitably disbursed and that the uses to which technique is applied are humanly healthy.

At rock bottom, I suggest, the most criminal use of technologies would be to deactivate brain cells. I allude to the kind of 1984 scenario in which human beings become more programmed than programming, in which technology has been used to perform a frontal lobotomy on human intentionality.

I suppose the crucial questions for teachers to ask about any educational technology are "Who stands to gain most from this" or "Whose interests is it serving?" Most modern educational technology is very expensive to develop and therefore the monied classes are likely to be the chief sponsors. They will want a good profit. There is always a danger, therefore, that the inventor's dream will be appropriated by Mammon. There is also the danger, now oft recited, of technology giving more power to the "already haves" and so increasing the societal divide between a technological rich and a relatively unassisted poor.

Schools have a vital part to play in teaching all children about how tools work, how to gain access to tools and how to use them. Indeed schools should go beyond this to ensure that all children get the opportunity to design and make tools. By "tools" I mean anything which will give them an edge, a lever, anything that will augment their power. Junior primary schools tend to do better in this respect than other levels. Unfortunately, 
we allow the very young to play and invent but tend to move into an instructional top-down mode as children move up through the school.

It is my view that educational technology will be best and most healthily used in schools which are already, in my terms, technological communities in their own right; that is, schools where making believe, designing, making things and making things work are an organic part of the culture. Such a school will not be one where technologies are "laid on" students. Students will have access to demystified technologies and will be expected to make technologies work for them. They will control and use available tools.

An important task of school is to ensure that whatever educational technology is used is demystified as far as possible. It is not good for children as consumers to view the technology as magic. They need to be taken behind the veneer to see the workings wherever possible.

Now the fact, as I have already suggested, is that Australian schools, like most schools in the Western world, tend not to be places where children make things and use technologies. Too many schools still operate on a paradigm of instruction rather than construction when it comes to learning theory. The epistemology of knowledge implicit in much of what schools do is based on an outmoded notion that knowledge can be transmitted from one head to another. Once this notion is explicitly or implicitly embedded, then inevitably the learner is placed in the role of recipient rather than actor. Technologies injected into such a regime are likely to be drummed into the service of instruction rather than of learning as an act of designing and constructing.

In facing its economic challenges, Australia urgently needs to come to terms with this. Almost all populist media and professional academic commentators are now agreeing that our economic future will depend on our productive capacity, especially the capacity to add value contributed by brain power.

"From the first to the final years of schooling the fundamental task of teachers, whatever they are teaching, is to increase the productive application of brain power in ever changing contexts in the face of ever changing problems. Students cannot gain power over all technologies and tools but they must learn how to use some and, in that learning, to develop the potential to learn other things when required. At the same time as they learn how to apply what they know, students need to become stronger and stronger in their confidence to "give it a go" when confronted with the unfamiliar and unforeseen. This, it seems to me in my conversation v; with people in business and industry, is what the economy needs above all else. This also seems to be congruent with the spirit of endeavour our national leaders are seeking."

(From "Creativity in Education: Making Things", in Garth Boomer (1987). Changing Education, Commonwealth Schools Commission, Canberra) 
This is the kind of thinking I bring to this important national conference. I therefore applaud the emphasis on the centrality of learning in your theme. From my limited viewpoint, designers of educational technology, at the cutting edge, are indeed taking a constructional rather than instructional view of learning. I find in the popular literature about educational technology which is linguistically accessible to me, encouraging signs that designers do recognise the importance of social interactivity in learning and that they are moving away from reductive conceptions of the human mind as data bank or tabula rasa. Advanced software is assuming that active minds will need to be challenged rather than moulded.

It is my hunch that the greatest challenge at this time is not so much what new technologies to invent, but rather how to adapt and match existing technologies to the real, complex contexts of education, be it in classrooms, industries or across distances. The problem is how to make it easily, and cheaply, usable by practitioners. Experiments in distance education by satellite show that wonderful things can be done, but at a price which may prove prohibitive and with an exceptionally high muscle-to-weight ratio in terms of people working to make the technology available as compared with end users and beneficiaries. We have distinct problems with economics of scale in this large and widely spread country.

It is not, however, just a matter of the cumbersome logistical or resource blocks associated with the technologies themselves. There is, I suspect, especially in our ageing teaching force, a huge weight of inertia, of comfortable habit which collectively constitutes a kind of institutional immunology to new technologies. It is not so much a Luddite mentality, or a fear of the mystical, as a kind of complacency or cottage industry complex, almost a romantic clinging to "natural" teaching regimes.

But then, on reflection, this smacks too much of pompous negative judgement of my colleagues. A greater problem in the take up of educational innovation may be the lack of time in schools: time to learn new skills in the application of technologies; time to design and implement new courses; time to experiment and to make mistakes without penalty; time, and support, to ride through the crises of nerve, the temporary deskilling, which always occurs when we take up new approaches. An important factor in teachers' persevering with a new technique is being able to imagine that things will be easier or better when the technique is mastered. Therefore, to introduce successfully on a broad scale any of the technologies which will be considered at this conference, it will be necessary to capture the imagination of teachers, not at the "gee-whiz" level, but at the level of imaginable tangible benefits from practice. This means making available authentic demonstrations of success by ordinary teachers working in a "warts and all" context. 
Introduction of new technologies also carries with it a substantial bill for in-service and pre-service training and development. This leads me to give a brief preview of a major report which is about to be presented to $\mathrm{Mr}$. Dawkins, Minister of Employment, Education and Training, entitled Teachers Learning: Improving Australian Schools Through Inservice Training and Development of Teachers. This report arises from a project which I chaired, initially as Chair of the Commonwealth Schools Commission.

It makes a strong case for the affording of the highest priority in the funding of Australian schooling to the training and development of teachers in the context of a nation striving to develop a productive culture and to unleash the potential of its collective brain power.

The report draws parallels between the training and development needs in education and industry. We need to promote a supportive designing/ learning climate first in schools and then in workplaces so that people in this country will go on learning for their own benefit and the benefit of the nation.

In comparing the commitment of IBM and BHP to staff development, in money terms, with the commitment of education systems, the report concludes that there is a considerable need to increase the resources committed by education systems to teacher inservice training and development. The school is seen as the focus of change and development and it is recognised that learning-on-the-job in relation to school improvement goals is likely to be more successful than decontextualised training conferences on a one-off basis.

This conference would do well, then, to consider some of the hard practical and political questions of how to win and provide support for the training and development which must accompany the introduction of new technologies. It should also try to catch the current rising wave of support for economies of scale which might come from a national effort.

Your Society, if I might be slightly playful, must not be caught sitting on its ASET.

This is a most timely conference, coinciding with new moves to consider national curriculum frameworks. At recent meeting of Directors of Curriculum, technology was considered as an area where profitable work could be done in fostering national collaboration. This is also a time when there is a national tide of realisation that the old educational ways will no longer carry us through.

I am therefore confident that the outcomes of this gathering will have a ready audience both in schools and in industry. I am certain also that politicians are ready to hear soundly reasoned advocacy for technological advances which will improve the quality of education in Australia. 
It is with a sense of anticipation and expectation of a personally steep learning curve that I now embark with you on the course of the conference. When we reconvene to reflect and consolidate on Thursday, I am sure that we shall all be wiser and better prepared to attack our individual and collective challenges, bristling with new ideas.

\section{Part Two-Designing For Learning: CODA}

At the end of a conference there are many questions we can ask:

- What has it all meant? (Collectively to us or personally to me?)

- What were the highlights / frontiers?

- Where were the weak spots?

- So what?

- Where do we go from here?

I would like this session to be one where we do some reflection, some constructive "critiquing" and some imagining of where to go next. It may also be that we will make some resolutions.

This is the process I propose. I shall continue to play out my role as receptive but judiciously sceptical teacher for a short time, in effect giving you some of my responses to the conference as I experienced it: a partial view but maybe a useful provocation for discussion. Then I suggest that we hear from several people that I have spotted at the conference who seem not afraid to have a say. From this base we shall throw the session open for a free-for-all with the focus on "so what" and "where to from here", giving special consideration to ASET's future. (What should it fight for? What should it stand firm on? etc.)

Before I begin, I am pleased to be able to join the strength by offering a small video stimulus. You will recall that at the beginning I compared myself with Alice about to enter Wonderland. It is fitting therefore that I should offer a coda. What did Alice make of it all? I think she confirmed that "software may come and hardware may go but warmware must go on forever".

[At this point a short video clip showed Alice bewildered in a tertiary institute while voices over sang "Expert, Expert" to the tune of "Inchworm, Inchworm"].

I am grateful to Anne Campbell who wrote and produced this piece some years ago not knowing that it would one day be shown here. It was Anne who introduced me to the new term of "warmware", flesh and blood human contact, affect, social interaction in a spirit of friendship and empathy. Of course, I do not presume to say to any of you here that you are any more limited than I. I include myself, and you, without discrimination, in the category of "menacing expert". Two months ago, at 
an international seminar on language and learning, I gave a paper called The Helping Hand Strikes Again, in which I warned of the possible toxicity of any outside specialists in education purporting to help classroom teachers. I suggested that the teacher needs to be able to be "poly attentive" in order to deal with "messes" and that specialists with neat technical fixes could in fact lead them into a state of "selective inattention": that is, a state in which they selectively define their problems and conveniently edit out or ignore events and details which would render their project messy.

This is all by way of saying that I want to warn us all to be humble and diffident about helping too readily. Only when we have indwelt with great subtlety in the contexts and challenges of teachers and industry trainers should we presume to offer advice and then probably only when we're asked. The most healthy situation for us is to be commissioned to help teachers who are trying to solve particular problems. If we impose our solutions onto their imagined problems, we are indeed likely to end up being benevolent menaces.

You've probably twigged that I am perilously close to doing precisely what I warn against: presuming to pass judgement, helpfully, on this conference when I haven't been commissioned to do so.

So without trying to be helpful, let me simply be tactless and say what I think, knowing that you will be quite irreverent in the session that follows. I am not stirring for stirring's sake. I'm going to be what I said I would be: a judiciously sceptical teacher. So, what do I think under just a few headings.

\section{I - Technocentricity}

It's funny. I didn't really feel at sessions, with a few exceptions, that I was at an education conference. I found myself at a technology and media conference. From time to time, I heard mention of learners but by and large the emphasis was on hardware and software rather than warmware. I found a surprising lack of talk about curriculum theory and learning theory (and curriculum practice and learning practice), detailed analysis about the real world contexts of teachers, students, trainers or employees in real sites.

Learners as designers, even teachers as designers, were rarely mentioned. We heard mainly about instructional materials designers, some perhaps wishing to bypass teachers. I heard a lot about what technologies can do but little evaluation of what they have actually done for real teachers and students, in terms of improving learning outcomes. You won't convince me until I hear from teachers that the techniques have worked for teachers and students in tangible ways. You probably won't convince politicians either, unless they want "you beaus" stuff for political ends. Are we a little naive politically? Learning outcomes and performance indicators are all 
the rage and yet few of us here have evaluated what we offer by means of hard-edged performance indicators.

Bob Miller was one of the few who put forward an explicit analysis of the complex learning act and who then, humbly but firmly, placed technology (or learning media) in a serving role within a wider complex.

He helped me to understand that much of what is called instructional design is really "message design". Messages are important but they are but one element of a fully designed learning enactment. I say all this neither as a technophobe nor a technophile. I was greatly impressed by much of the new age gear, but I think that it needs ruthless grounding in the realities of school/institutional and political life, and then in Deiter's terms seen clearly as "an aid in the hands of the teacher". Technocentricity may also explain why there was little talk of Mr Dawkin's goals for Australian education, about the new era of accountability and about the crisis facing public education in this country. (It was a strangely apolitical occasion, for me as one who has just spent four years in Canberra working with the Minister of Education.)

\section{II - Where Were The Teachers?}

This was a conference largely of people from TAFE, the higher education sector industry and the technology industry. The dynamic of the conference would have changed I'm sure if we had had some primary and secondary teachers talking about how they use or don't use technique in designing for learning in their classrooms. It would also have helped, I think, to hear more about how teachers have handed over the means of production to students (at all levels) as designers (as the students here have been involved in video recording of this event). (One or two people not presenting seemed to have much to offer on this topic.)

Does ASET wish to remain a largely post-schooling society? I hope not. Why did the teachers not come?

\section{III - How Low Can You Go?}

I'm inclined, being a simple soul, to think that the present performance of teachers in using anything but language and chalk is so dismal that we would do well to go back to simple technological basics before trying to leap into the sophisticated fast lane.

Allan Yarrow's and Jan Millwater's session confirmed for me the view that schools are largely language-bound institutions and that tertiary institutions arc even more language bound. The abysmally unadventurous teaching (as a generalisation) in universities and colleges of advanced education, the twin monotones of talk and print, reproduce teachers who rarely dare to walk even mildly on the wild side. The multi-learning media/technology-as-learning-support revolution must begin with the training of our teachers. 
Bob Miller formally, and quite a few people informally, suggested that we must resist premature, new-technology distortion of our teaching and that maybe the prime challenge is to become proficient users of long-standing technologies. How well do we use overheads in schools, for instance? And, for heaven's sake, have a look at our exams! The HSC with various equivalents could not cope if it actually admitted audio, video or multimedia demonstrations of understanding in answer to a question.

We haven't even begun to scratch the surface of technology in education while the chief governors of education (exams and tests) remain slavishly print oriented. I suggest therefore that ASET might profit by revisiting educational fundamentals.

\section{IV - Honesty of Purpose}

I found Graham Parslow's forthright, pragmatic, no-nonsense approach to his "Q" packages refreshing. He admitted that some things are boring to teach and pretty low level in their demands on neurones anyway so why not use non-glossy but highly effective, self-teach computer assisted packages to do the drudgery. That leaves him free to do the more intellectually erotic things in big-chemistry. Such packages don't have options. You do them to learn something specific and the package, once entered, is linear.

I also found Henrietta Clark's presentation of the $\mathrm{ABC}$ as a provider of educational resource to be used by the teacher an example of no-nonsense honesty. The $\mathrm{ABC}$ does not pretend to teach. I suspect, however, that any materials which purport to teach are relatives of propaganda, even Sesame Street. Deiter Kamm helped me to understand two major roles for media one, in the presentation of complex illuminative demonstrations and, two, as vehicles for exploring territory.

I do worry a bit about some of the other instructional materials which are neither clearly focussed, low-level training regimes nor neutral resources waiting for teacher interpretation and use. Education is still massively colonised, overtly and cryptically, by a reductive behaviourist rat psychology. Often unwittingly, teachers work to a conduit metaphor of knowledge and a positive/negative reinforcement notion of motivation. Most text books and educational software packages are riddled with a kind of "confidence trick" view of learning. The aspirin cannot honestly be termed aspirin. It needs to be mixed with various kinds of honey. Learners need to be cajoled, won over, entertained.

Hence my worries about entertaining packages which are, in fact, very tightly framed but which give so-called choice or alternative pathways within the frame and purport to be interactive while ceding no real power to the user. These are materials which have very clear and palpable designs on students but which tend to disguise their intentions. (I'd like to have more discussion on this topic.) 


\section{V - So What for ASET?}

I have deliberately erred on the side of critique in making these remarks. Let me now be positive. I have learned heaps. I think that there are exciting possibilities in the technologies we have seen. I will encourage South Australian teachers to learn about them and use them. I am also full of admiration for the pioneering people who are out there doing the hard and often thankless exploratory yakka. It's all very well for people like me to criticise from an unthreatened position.

From what I have seen, ASET has a healthy future if it can with subtlety and energy exploit the moment:

"There is a tide in the affairs of men which taken at the flood leads to victory" (Julius Caesar)

As one who has chaired both a national and an international association, I know the difficulties of bringing about unity (while allowing diversity) ASET seems still to be floundering a little about its identity (arid is probably little more than an aggregation of affiliates). It seems also a 1ittle too remote, as I have suggested, from education in practice at all levels. If I am wrong on this score, or any other score, I know you will now correct me.

Here is my short but not exhaustive list of possible things to do:

1. Clarify the role and mission of ASET, especially national policy (And I, of course, plump for the emphasis on design for learning.)

2. Bid to the Commonwealth for a national education/industry research project (perhaps on remote distance modes - capitalising on the Brumby inquiry).

3. Increase the amount of evaluation of learning outcomes (hopefully to show that multimedia explorations lead to better learning).

4. Seek to apply pressures for reform at all levels in the setting of assignments (tests, exams, projects), so that students get credit for performance and production in and through media.

5. Include some student awards for design at each ASET conference.

6. Invite some teachers to present at the next conference.

7. Seek to set up a National Federation of like-minded associations and societies (e.g., Media Teachers, Computer Associations, Librarians, to form a more powerful lobby).

8. Push for a national institute of educational media and a national TV Education channel?

Please cite as: Boomer, G. (1988). EdTech'88 - designing for learning. Australian Journal of Educational Technology, 4(2), 91-102. http: / / www.ascilite.org.au/ajet/ajet4/boomer.html 